\title{
GAP ANALYSIS PROGRAM GIZI DAN KESEHATAN DI POSYANDU KABUPATEN BOGOR
}

\author{
(Gap Analysis of Nutrition and Health Program In Posyandu at Bogor District)
}

\author{
Ellis Endang Nikmawati ${ }^{*}$, Clara M Kusharto², Ali Khomsan², Dadang Sukandar ${ }^{2}$, dan Arum Atmawikarta ${ }^{3}$ \\ * Alamat Korespondensi: Program Studi Tata Boga, Jurusan PKK, Fakultas Pendidikan Teknologi dan \\ Kejuruan, Universitas Pendidikan Indonesia. Jl. DR. Setia Budhi No 229 Bandung Tlp. (022) 2033161 \\ Email: ellisen_nik@yahoo.com \\ 2 Departemen Gizi Masyarakat Fakultas Ekologi Manusia, Institut Pertanian Bogor, Bogor 16680 \\ 3 Badan Perencanaan Pembangunan Nasional, Bappenas Jakarta
}

\begin{abstract}
Revitalization of Integrated Service Center Post (Posyandu) is successful when focused to its main function as community institution services. Determine gap analysis program based on tangibles, reliability, responsiveness, assurance, empathy dimension. Exploratory and experimental designs was applied in this study, which was conducted at Darmaga and Ciomas district, Bogor Regency from March to August 2008. The data included primary and secondary data. The respondent in the experiment was 240 mothers of children under five years and 80 cadres. Gap analysis was used to know the expected and the real nutrition and health program of respondent. Totally 96 balita's mother, pregnancy and reproductive women and 16 cadres were involved in this study. The average of gap realization with standard tool -0,75; Tangibles dimension -0,35; Reliability -0,10; Responsiveness -0,37; Assurance -0,44, and Empathy -0,47, its mean that a tools accomplisment only 25\% (less); tangible dimension 65\% (enough); reliability 90\% (good); responsiveness dimension 63\% (enough); assurance dimension 56\% (less) and emphaty 53\% (less), respectively.
\end{abstract}

Key words: posyandu performance, nutrition education, gap analysis

\section{PENDAHULUAN}

\section{Latar Belakang}

Pembangunan merupakan upaya pemerintah bersama masyarakat dalam mensejahterakan bangsa. Keberhasilan pembangunan nasional ditentukan oleh adanya sumber daya manusia di berbagai sektor. Kualitas SDM ditandai dengan fisik dan mental yang kuat, kesehatan yang prima dan pendidikan yang baik serta menguasai ilmu pengetahuan dan teknologi terkini. Peningkatan kemajuan dan kesejahteraan bangsa sangat tergantung pada kemampuan dan kualitas sumberdaya manusianya. Ukuran kualitas SDM dapat dilihat pada indeks pembangunan manusia (IPM), sedangkan ukuran kesejahteraan masyarakat dapat dilihat pada tingkat kemiskinan dan status gizi masyarakat. IPM merupakan ukuran yang dipengaruhi oleh tingkat ekonomi, pendidikan dan kesehatan. Kualitas SDM Indonesia saat ini masih tertinggal dibandingkan negara lain.

Hal ini ditunjukkan oleh posisi IPM Indonesia pada tahun 2007 yang berada pada urutan 112 dari 175 negara. Posisi IPM negara ASEAN lainnya lebih baik dibandingkan 140
Indonesia, seperti Malaysia pada tahun 2006 urutan ke 56, Filipina ke 77, Thailand 67, Singapura 22, dan Brunai 25. Persentase penduduk miskin juga menjadi faktor penting penentu IPM. Pada tahun 2009 tingkat kemiskinan di Indonesia masih mencapai $14,15 \%$ yang berarti 32,5 juta jiwa masih berada di bawah garis kemiskinan (Berita Resmi Statistik, 2009). Gizi buruk (severe malnutrition) adalah terjadinya kekurangan gizi menahun. Menurut Departemen Kesehatan (2004), tahun 2003 terdapat 27,5\% (5 juta balita kurang gizi), 3,5 juta anak (19,2\%) gizi kurang, dan 1,5 juta anak gizi buruk $(8,3 \%)$.

Berdasarkan data di atas maka kasus gizi buruk di Indonesia termasuk kategori tinggi. Penyebab gizi buruk dipengaruhi oleh banyak faktor yang saling terkait, pada umumnya penyebab anak kekurangan gizi disebabkan karena asupan makanan yang kurang sehingga anak mudah dan sering sakit atau terkena infeksi (Riskesdas, 2007). Mereka yang masih dapat bertahan hidup akibat kekurangan gizi yang bersifat permanen kualitas hidup selanjutnya mempunyai tingkat yang sangat rendah dan tidak dapat diperbaiki meskipun pada usia berikutnya kebutuhan 
gizinya sudah terpenuhi. Istilah "generasi hilang" terutama disebabkan pada awal kehidupannya sulit memperoleh pertumbuhan dan perkembangan secara optimal.

Posyandu dan puskesmas sebagai ujung tombak dalam melakukan deteksi dini dan pelayanan pertama menjadi vital dalam pencegahan kasus gizi buruk saat ini. Penggunaan kartu menuju sehat dan pemberian makanan tambahan di posyandu perlu digalakkan lagi. Tindakan cepat pada balita yang dua kali berturut-turut tidak naik berat badan segera mendapat akses pelayanan dan edukasi lebih lanjut, dapat menjadi sarana deteksi dan intervensi dalam bentuk intervensi pendidikan gizi yang efektif. Termasuk juga peningkatan cakupan imunisasi untuk menghindari penyakit yang dapat dicegah, serta menjaga kebersihan personal maupun lingkungan.

Program gizi dan kesehatan di posyandu, banyak sekali mengalami kendala sehingga dapat menghambat kelancaran pelaksanaan program tersebut. Untuk itu maka perlu dilakukan penelitian tentang bagaimana pelaksanaan KIE dan kesenjangan yang ada antara harapan dan realisasinya di lapangan, sehingga dapat diperoleh suatu rekomendasi untuk pengembangan program gizi dan kesehatan yang lebih baik.

\section{Tujuan Penelitian}

Tujuan umum dari penelitian ini adalah menganalisis kesenjangan (gap analysis) program gizi dan kesehatan di posyandu yang ada di Kecamatan Darmaga dan Ciomas Kabupaten Bogor. Tujuan khusus dari penelitian ini adalah :

1. Menganalisis realisasi program di posyandu berkaitan dengan SDM: kader, ibu balita, petugas kesehatan, keterlibatan aparat/ Toma/Toga, anggaran, fasilitas, alat dan bahan.

2. Menganalisis gap/kesenjangan program gizi dan kesehatan di posyandu berdasarkan dimensi; tangibles, reliability, responsiveness, assurance, empathy.

\section{METODE PENELITIAN}

\section{Desain, Waktu dan Lokasi Penelitian}

Penelitian ini dilaksanakan di Kecamatan Ciomas dan Kecamatan Darmaga Kabupaten Bogor Propinsi Jawa Barat. Desain dalam penelitian ini adalah exploratory dan eksperimental. Penulis terlibat dalam pengambilan data dan intervensi yaitu menjadi instruktur dalam pendidikan gizi pada ibu balita dan kader di posyandu terpilih, yang dilaksanakan dari bulan Febuari sampai September 2008. Data untuk mengetahui gap dari program gizi dan kesehatan di posyandu di peroleh dari pengguna jasa pelayanan posyandu yaitu ibu balita, ibu hamil dan WUS dilaksanakan pada bulan Juli sampai Agustus 2009. Data sekunder diperoleh dari petugas puskesmas yang terkait dengan kegiatan posyandu dan Kecamatan Ciomas dan Darmaga Kabupaten Bogor.

\section{Jenis dan Cara Pengumpulan Data}

Jenis data yang dikumpulkan adalah data primer dan data sekunder, pengumpulan data primer dilakukan dengan menyebar kuesioner untuk ibu balita dan kader posyandu. Data yang dikumpulkan meliputi data posyandu, kader, rumah tangga, balita dan ibu balita. Data posyandu meliputi kondisi fisik posyandu dan aktivitasnya. Data kader dan ibu balita meliputi sosial ekonomi, gaji sebagai kader, dan pendidikan. Kuesioner di ujicoba sebelum dipergunakan dalam penelitian ini. Ujicoba dilakukan di luar lokasi penelitian. Data sekunder diperoleh dari instansi terkait.

Gap analisis dilakukan untuk melihat bagaimana kualitas pelayanan (service quality) dari posyandu kepada para pengguna jasa yaitu ibu balita, ibu hamil dan WUS, dan seberapa jauh perbedaan antara kenyataan dan harapan pengguna jasa atas layanan yang mereka terima. Data yang dikumpulkan meliputi lima dimensi yaitu tangibles (fisik), reliability (keandalan), responsiveness (ketanggapan), assurance (jaminan), dan empathy.

Penelitian dilakukan untuk mengetahui bagaimana harapan dan realitasnya dari program gizi dan kesehatan di posyandu sehingga akan diketahui kesenjangan dari program gizi dan kesehatan tersebut. Untuk memperoleh data gap antara realisasi dengan harapan dari program posyandu yang menjadi responden adalah yang telah menjadi anggota minimal 5 tahun yaitu ibu balita, ibu menyusui, dan WUS sebanyak 6 orang dari setiap posyandu terpilih yaitu 16 posyandu mengikuti jumlah posyandu yang telah ditentukan pada pengambilan data sebelumnya, total responden sebanyak 96 orang dan kader sebanyak 16 orang dari 16 
posyandu, kepala Puskesmas dan bidan sebagai pembina posyandu di Kecamatan Darmaga dan Ciomas.

\section{Pengolahan dan Analisis Data}

Analisis data meliputi penghitungan rata-rata, standar deviasi, nilai terkecil, nilai terbesar, dan proporsi. Lima statistik dasar dihitung untuk semua variabel yaitu umur, pendidikan, pendapatan, pengeluaran. Hasilnya kemudian ditampilkan dalam tabel dan diagram-diagram.

Untuk melihat apakah suatu perusahaan atau program berjalan dengan baik atau tidak maka perlu adanya upaya untuk dapat mempertahankan kualitas dalam pelaksanaannya, Lupiyoadi (2001) menjelaskan bahwa persoalan kualitas dalam dunia bisnis kini sepetirnya sudah menjadi "harga yang harus dibayar" oleh perusahaan agar dapat tetap survive dalam bisnisnya. Walaupun posyandu adalah merupakan lembaga yang tidak menghasilkan keuntungan secara langsung dalam bentuk rupiah tetapi merupakan lembaga yang memberikan jasa pelayanan terhadap masyarakat, dalam menjalankan tugasnya akan berhasil apabila selalu menjaga dan meningkatkan kualitas pelayanannya.

Salah satu pendekatan kualitas pelayanan yang banyak dijadikan acuan dalam riset pemasaran adalah model SERVQUAL (Service Quality) yang dikembangkan oleh Parasuraman, Zeithaml, dan Berry (1996) dalam Lupiyoadi (2001) bahwa SERVQUAL dibangun atas adanya perbandingan dua faktor utama yaitu persepsi pelanggan atas layanan yang nyata mereka terima (perceived sevice) dengan layanan yang sesungguhnya diharapkan (expected service). Jika kenyataan lebih dari yang diharapkan, maka layanan dapat dikatakan bermutu sedangkan jika kenyataan kurang dari yang diharapkan, maka layanan dikatakan tidak bermutu. Dan apabila kenyataan sama dengan harapan, maka layanan memuaskan. Dengan demikian, Service Quality dapat didefinisikan sebagai seberapa jauh perbedaan antara kenyataan dan harapan pelanggan atas layanan yang mereka terima/ peroleh (Parasuraman et al, 1998) dalam Lupiyoadi (2001).

Kesenjangan $(G)$ = Rata-rata program gizi dan kesehatan di posyandu yang diharapkan dikurangi rata-rata realisasi program gizi dan kesehatan di posyandu.
Rumus yang digunakan untuk menghitung gap antara realisasi dengan standar alat yang dimiliki posyandu:

$\mathrm{G}_{1} i=\underline{\mathrm{R} i-\mathrm{S} i}$ gap antara realisasi dengan

$\mathrm{Si}$ standar alat yg dimiliki posyandu

$\mathrm{G}_{2} i=\underline{\mathrm{H} i-\mathrm{S} i}$ gap antara harapan dengan

$\mathrm{Si}$ standar alat yg dimiliki posyandu

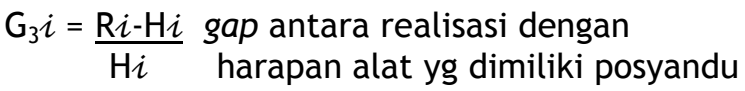

$\mathrm{G} i=\underline{\mathrm{R} i-\mathrm{H} i}$ gap antara realisasi dengan

$\mathrm{Hi}$ harapan program gizi dan kesehatan di posyandu

Keterangan :

$\mathrm{G}=$ nilai Gap

$\mathrm{R}=$ Rata-rata nilai realisasi alat yang dimiliki posyandu

$\mathrm{H}=$ Rata-rata nilai harapan dari pengguna terhadap alat yang ada di posyandu

$\mathrm{S}=$ Standar alat posyandu berdasarkan hasil diskusi dengan para pakar

Hasil dari perhitungan apabila nilai gap < 60\% termasuk pada kategori kurang, bila nilai gap antara $60-<80 \%$ termasuk kategori cukup, nilai gap $>80-<100 \%$ termasuk kategori baik dan biula nilai gap >100\% termasuk kategori sangat baik. Kriteria status gap digolongkan sebagai berikut : jika kisaran gap $1<\overline{\mathrm{G}}<-0,4$ atau $0<(1+\overline{\mathrm{G}}) \times 100 \%<60$ maka kategori gap termasuk pada kategori kurang, kisaran gap $-0,4<\overline{\mathrm{G}}<-0,2$ atau $60<$ $(1+\bar{G}) \times 100 \%<80$ maka kategori gap termasuk pada kategori cukup, kisaran gap $0,2<\overline{\mathrm{G}}<0$ atau $80<(1+\overline{\mathrm{G}}) \times 100 \%<100$ maka kategori gap termasuk pada kategori baik, dan jika kisaran gap $\overline{\mathrm{G}} \geq 0$ atau $(1+\overline{\mathrm{G}}) \mathrm{x}$ $100 \% \geq 100$ maka kategori gap termasuk pada kategori sangat baik.

Standar alat diperoleh berdasarkan langkah-langkah sebagai berikut :

1. Penetapan standar awal dari alat-alat posyandu meliputi jenis dan jumlah berdasarkan perhitungan rasio antara pengguna sebanyak 50 orang (balita, ibu hamil, WUS, dll) yang datang ke posyandu dengan jumlah alat yang diperlukan sesuai dengan jenis pelayanan yang diberikan.

2. Diskusi dengan para pakar, yang terdiri dari dosen, pembimbing, dan pakar dari Dinkes Kabupaten Bogor dan Dinkes 
Propinsi Jabar, untuk mendapatkan standar alat.

3. Jika pendapat pakar hasilnya $>50 \%$ maka standar alat akan mengikuti saran para pakar berdasarkan modus (angka atau jumlah yang sering muncul) dari jumlah alat tersebut. Apabila $<50 \%$ maka standar alat mengikuti standar alat yang sudah ditetapkan peneliti.

\section{HASIL DAN PEMBAHASAN}

\section{Karakteristik Ibu Balita dan Kader Posyandu}

Kader posyandu baik pada kontrol maupun intervensi rata-rata berusia sekitar 40 tahun. Pendidikan kader rata-rata setingkat SMP dengan lama pendidikan 9,2 tahun pada posyandu kontrol dan 7,4 tahun pada posyandu intervensi. Pendapatan rumah tangga kader posyandu kontrol lebih rendah dari kader posyandu intervensi yaitu rata-rata sebesar $\mathrm{Rp}$ 255000/kapita/bulan pada posyandu kontrol dan rata-rata Rp 297000/kapita/bulan pada posyandu intervensi. Lama pendidikan ibu balita di desa intervensi setara dengan SMP kelas 1 , lebih rendah dibanding desa kontrol yang setara dengan SMP kelas 2. Jadi, ibu balita hanya mempunyai ijasah SD, sedangkan umur ibu balita baik pada kelompok kontrol maupun intervensi rata-rata berusia 30 tahun.

Pendapatan dan pengeluaran ibu balita menunjukan rata-rata di desa kontrol adalah Rp 240500/kapita/bulan dan desa intervensi Rp 235000/kapita /bulan, hampir semua responden pendapatannya masih di bawah garis kemiskinan, hal tersebut terlihat dari sebagian besar pengeluaran digunakan untuk kebutuhan pangan desa kontrol 56,4\% dan desa intervensi sebesar $53,5 \%$. Besarnya pengeluaran pangan lebih dari setengahnya dipergunakan untuk memenuhi kebutuhan makan maka hal tersebut menunjukkan bahwa penduduknya masih tergolong kurang sejahtera. Kader bekerja sebagai ibu rumah tangga $(80,0 \%$ kelompok kontrol dan $92,5 \%$ kelompok intervensi). Sebagian kecil bekerja sebagai pedagang, Pegawai Negeri Sipil (PNS), jasa dan lainnya. Ibu balita sebagai responden di kelompok kontrol $(75,8 \%)$ dan intervensi $(85,8 \%)$ pada umumnya tidak bekerja yaitu menjadi ibu rumah tangga.

Kader posyandu kontrol bekerja ratarata selama 11 tahun, kader posyandu intervensi rata-rata 12 tahun. Keadaan tersebut menunjukkan bahwa mereka cukup lama dalam menjalankan tugasnya sebagai kader . Umumnya mereka tinggal di desanya selama 28 tahun atau lebih. Dengan demikian mereka sudah cukup dikenal oleh lingkungan sekitarnya. Jumlah kader pada posyandu ratarata sekitar 5 orang, dengan jumlah anggota yang dilayani sekitar 30 sampai 75 balita. Untuk pelaksanaan kegiatan posyandu tidak didukung dengan anggaran rutin, hanya 2,5\% posyandu kontrol dan $12,5 \%$ posyandu intervensi yang mendapatkan anggaran rutin, sehingga pengelola posyandu merasa kesulitan dalam menjalankan tugasnya terutama dalam pengadaan PMT untuk balita, sebab apabila PMT tidak ada maka balita yang berkunjung ke posyandu mengalami penurunan.

Untuk kelancaran kegiatan posyandu, salah satu wakil kader dari setiap posyandu mengikuti pertemuan bulanan baik di desa, puskesmas maupun kecamatan. Pertemuan tersebut merupakan kegiatan koordinasi yang dilakukan oleh puskesmas terutama apabila menghadapi pekan imunisasi nasional, bulan vitamin A, serta pengisian laporan bulanan. Dengan adanya pertemuan tersebut diharapkan program posyandu dapat direncanakan dengan lebih baik.

Program di posyandu salah satunya adalah pelayanan untuk ibu hamil diantaranya adalah pemeriksaan kesehatan ibu hamil, pemberian imunisasi TT ibu hamil dan tablet besi untuk mencegah terjadinya anemia gizi besi. Seperti yang dikumukakan oleh Muslimatun (2001) gizi selama kehamilan penting untuk kesehatan ibu, kualitas kehamilan, dan keselamatan hidup bayi. Perbaikan keadaan gizi ibu selama kehamilan tidak hanya bermanfaat untuk ibu, tetapi juga untuk mengoptimalkan pertumbuhan bayi mereka di dalam dan di luar kandungan. Di Indonesia, lebih dari separuh ibu-ibu hamil menderita anemia defisiensi besi dan sepertiga dari ibu-ibu hamil dan menyusui mempunyai status vitamin A yang tidak adekuat. Defisiensi besi dan vitamin A mungkin mengakibatkan pengaruh negatif terhadap kualitas kehamilan dan pertumbuhan bayi.

Kegiatan yang dilakukan oleh kader di posyandu hampir semuanya $(>90 \%)$ melakukan penimbangan, pencatatan hasil penimbangan ke dalam kartu menuju sehat (KMS), penyuluhan gizi dan kesehatan, memberikan PMT untuk balita dan ibu hamil, juga memberikan rujukan ke Puskesmas, pemberian kapsul vitamin A, masing-masing $(85 \%$ dan $72,5 \%)$ memberikan tablet besi dan pemberian 
kapsul yodium $42,5 \%$ dan $40 \%$. Kader pernah mengikuti pelatihan pangan, gizi dan kesehatan. Pelatihan yang diikuti kader ratarata 3,8-3,9 kali. Pelatihan ini sangat membantu para kader di dalam menjalankan tugasnya. Pelatihan diselenggarakan di puskesmas, kecamatan, desa, dan kabupaten.

\section{Gap Analysis Program Gizi Dan Kesehatan Di Posyandu}

Salah satu hal terpenting dalam mengevaluasi kepuasan pelanggan adalah dengan melakukan pengukuran tingkat kesenjangan antara harapan yang diinginkan pelanggan dan nilai performa jasa dan layanan yang diberikan oleh pelanggan. Kesenjangan ini disebut sebagai gap, nilai kesenjangan ini akan memberikan informasi mengenai seberapa besar suatu produk dan jasa telah memberikan kesan bahwa harapan adalah suatu tingkat ideal yang diinginkan pelanggan. Analysis gap dilakukan untuk mengetahui kesenjangan antara performa dari atribut produk dan layanan dengan persepsi atau keinginan yang diharapkan oleh pelanggan (Nugroho, 2004). Uraian tersebut menunjukan bahwa gap anlysis bisa digunakan untuk mengukur tingkat kesenjangan antara harapan yang diinginkan oleh pelanggan dalam hal ini yang dimaksud pelanggan adalah pengguna posyandu seperti ibu balita, ibu hamil dan WUS dengan jasa/pelayanan yang diberikan oleh posyandu. Seperti yang dijelaskan Lupiyoadi (2002) yang dimaksud pelanggan adalah seseorang yang beberapa kali datang ke tempat yang sama untuk memenuhi apa yang diinginkan untuk mendapatkan suatu jasa.

Untuk kelancaran pelaksanaan program maka posyandu harus memiliki alat dan bahan diantaranya adalah alat-alat untuk penimbangan dan pelaksanaan program lainnya. Hasil observasi sebanyak 54,5\% posyandu belum memiliki sarana yang memadai. Ada pun permasalahan yang sering dikeluhkan kader antara lain timbangan sudah rusak, tidak tersedia buku register, kurangnya sarana untuk penyuluhan, serta tempat untuk kegiatan posyandu kurang memadai. Menurut Jazid (1991) sarana yang tersedia di posyandu merupakan hal yang sangat penting dan mempengaruhi kelancaran pelayanan serta mempengaruhi mutu dan jenis kegiatan di posyandu.

Sumber pemberi alat-alat yang ada di posyandu sebagian besar dari donatur sebanyak 53,4\% seperti dari Yasmina (WFP), berasal dari Pemerintah 34,5\%, serta uang kas $12,1 \%$ yang berasal dari iuran anggota posyandu yang dipungut setiap kali penimbangan besarnya berkisar antara Rp.500 - 1000, sebagai pengganti PMT untuk balita. Untuk kelancaran pelaksanaan program di posyandu selain alat maka obat-obatan atau bahan yang diperlukan adalah obat-obatan untuk imunisasi yang pada umumnya dibawa oleh bidan pada saat penimbangan di posyandu, sedangkan obat penurun panas, oralit dan pil besi tersedia hanya di beberapa posyandu.

Tempat pelaksanaan program posyandu khususnya penimbangan adalah di gedung sendiri sebesar $56,2 \%$, di rumah kader dan halaman rumah tokoh masyarakat masingmasing $18,8 \%$, serta di puskesmas pembantu $6,2 \%$. Luas bangunan cukup beragam mulai dari $1 \times 3 \mathrm{~m}^{2}(6,3 \%), 2 \times 2 \mathrm{~m}^{2}(43,8 \%), 3 \times 4 \mathrm{~m}^{2}(31,3 \%)$ dan luas $6 \times 8 \mathrm{~m}^{2}(6,3 \%)$. Asal bantuan dana untuk pembangunan gedung posyandu pada umumnya adalah berasal dari imbal swadaya Pemerintah Daerah Bogor tahun 2007, dan swadaya masyarakat. Besarnya dana untuk pembangunan gedung posyandu berasal dari imbal swadaya sebesar duapuluh juta ruoiah sebanyak $25 \%$, hasil dari swadaya masyarakat sebesar Rp. 1.750.000 sebanyak 12,5\%. Dana untuk pemeliharaan tetapi berdasarkan hasil penelitian $(87,5 \%)$ tidak ada dana untuk pemeliharaan gedung. Biaya pemeliharaan gedung berasal dari sumbangan kader $(12,5 \%)$. Kader tidak memperoleh insentif (100\%) mereka bekerja secara sukarela.

Untuk kelancaran pelaksanaan kegiatan di posyandu maka diperlukan biaya yang tidak sedikit diantaranya untuk pengadaan PMT, ATK, pengadaan alat-alat dan baju seragam kader. Sumber dana untuk pengadaan PMT $(50 \%)$ berasal dari uang kas atau iuran angota posyandu, $(43,8 \%)$ berasal dari donatur, dana untuk pengadaan ATK $(68,8 \%)$ berasal dari uang kas, pengadaan alat penimbangan $(68,8 \%)$ berasal dari donatur dan (25\%) dari Puskesmas. Sedangkan untuk pengadaan baju seragam $(43,8 \%)$ berasal dari donatur, $(31,2 \%)$ dari Puskesmas dan $(18,8 \%)$ berasal dari uang kas. Realisasi insentif dan baju seragam yang diterima kader tidak ada, hanya $(6,3 \%)$ kader menerima baju seragam lima tahun yang lalu. Kader mempunyai harapan mendapatkan insentif dari pemerintah setiap bulan (93,8\%), setiap tahun mendapatkan baju seragam $(75,0 \%)$ dan $(100 \%)$ mengharapkan adanya THR. Sedangkan harapan responden terhadap pelatihan gizi dan kesehatan diadakan setahun dua kali $(56,3 \%)$. 
Posyandu sebaiknya memiliki alat-alat yang standar sehingga dapat menunjang terhadap pelaksanaan kegiatan yang telah diprogramkan di posyandu, seperti pengukuran status gizi, pemeriksaan ibu hamil, ibu menyusui dan WUS, juga pelaksanaan KIE diantaranya memberikan penyuluhan kepada ibu-ibu sebagai anggota posyandu. Rata-rata anggota posyandu berjumlah 25 sampai 75 orang setiap posyandunya. Keberadaan alatalat di posyandu masih belum memadai seperti dikemukakan oleh Puspasari (2002) sarana dan prasarana di posyandu masih belum memadai sehingga menyulitkan kader untuk melakukan kegiatan. Yang paling dirasakan antara lain tempat pelaksanaan posyandu yang biasanya dilaksanakan di salah satu ruangan di kantor kepala kelurahan, polindes dan gedung PKK sehingga tidak memungkinkan untuk disediakan tempat bermain bagi balita. Selain itu buku register sering tidak lengkap yang tentunya menghambat sistem pencatatan. Standar alat yang dibutuhkan untuk melayani sekitar 50 orang, berdasarkan hasil diskusi dengan para pakar (expert judgement) yang terdiri dari Dosen, peneliti dari Puslitbang Gizi dan Makanan, bagian Promosi kesehatan dari Dinas Kesehatan Kabupaten Bogor, dan bagian Promkes dan Sie Keska dan Gizi Bina Yankes Dinas Kesehatan Propinsi Jabar, maka ditetapkan kelayakan alat/fasilitas yang sebaiknya di posyandu.
Gambar 1. menunjukan bahwa antara realisasi dengan harapan ( $\mathrm{R}-\mathrm{H})$ masih terdapat gap yang besar artinya harapan masyarakat terhadap alat-alat yang dimiliki posyandu lebih tinggi dari pada standar dan realisasinya. Sedangkan gap antara harapan dan standar $(\mathrm{H}$ S) berada di bawah realisasi dengan standar (R-S).

Berdasarkan hasil penelitian timbangan digital realisasinya masih sangat kurang yaitu rata-ratanya 0,01 , keadaan tersebut bisa dimengerti karena harga dari timbangan tersebut mahal. Posyandu juga sebaiknya memiliki kelengkapan untuk pelaksanaan KIE seperti buku-buku yang berkaitan dengan gizi dan kesehatan, posterposter, leaflet, lembar balik, modul dan lainnya. Rata-rata gap antara realisasi dengan standar alat yang harus dimiliki oleh posyandu (R-S) adalah -0,75 artinya alat-alat yang dimiliki oleh posyandu pencapaiannya baru 25\%. Rata-rata gap berdasarkan harapan dengan standar (H-S) adalah $-0,23$ artinya bahwa harapan dari responden adalah $77 \%$. Rata-rata gap antara realisasi dengan harapan (R-H) -0,69. Artinya bahwa berdasarkan kenyataan alat-alat yang dimiliki pencapaiannya baru 31\%. (Dapat dilihat pada Tabel 1).

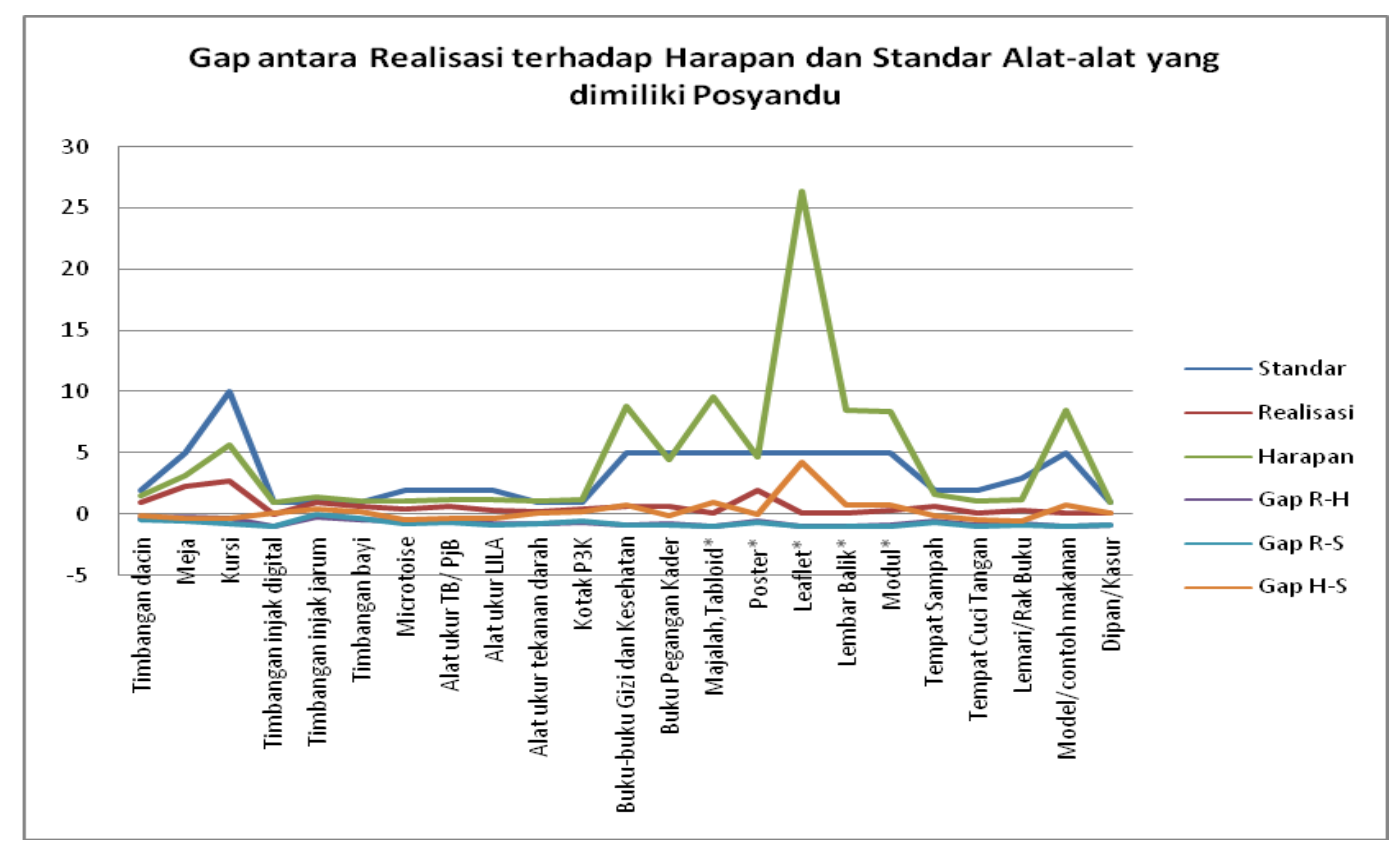

Gambar 1. Gap antara realisasi, harapan dan standar alat-alat yang dimiliki posyandu 

Salah satu yang menarik anggota mengunjungi posyandu adalah kenyamanan dari tempat tersebut, hasil penelitian menunjukkan bahwa responden yang merasa nyaman $(46,9 \%)$, yang merasa kurang nyaman (40,6\%). Berdasarkan hasil observasi di lapangan menunjukkan bahwa ketidaknyaman yang dialami responden, karena masih ada tempat yang digunakan untuk penimbangan balita tempatnya tidak memadai, yaitu di halaman salah satu rumah kader, tempatnya kurang luas, kurang bersih dan tempat menggantungkan timbangan dacin di parapara, apabila dilihat dari segi keamanan dan kenyamannya masih sangat kurang.

Posyandu sebagai tempat pelayanan kesehatan dan gizi sebaiknya selalu menjaga kebersihan dengan baik. Pengguna posyandu merasa tempat penimbangan/posyandu sudah bersih adalah $(59,4 \%)$, masih kurang bersih adalah $(33,3 \%)$. Alasan sekitar posyandu tidak bersih adalah karena tidak ada petugas khusus untuk kebersihan $(18,8 \%)$, tidak ada tempat sampah (15,6\%). Harapan responden agar posyandu menjadi bersih adalah $(17,7 \%)$ supaya disediakan tempat sampah, ada piket rutin dari ibu balita sebagai anggota posyandu $(14,6 \%)$, ada piket rutin dari kader $(4,2 \%)$.

Pelayanan kesehatan dan KB belum maksimal yaitu rata-rata $50 \%$. Pelaksanaan penyuluhan dengan menggunakan media masih sangat rendah, sedangkan harapan responden (100\%) agar fasilitas fisik memiliki kesesuaian dengan pelaksanaan kegiatan di posyandu. Penampilan kader dan bidan sudah baik yaitu masing-masing berpakaian rapih $100 \%$ dan $96,9 \%$, masing-masing (100\%) bersih dan sopan, serasi masing-masing $(86,5 \%)$ dan $(100 \%)$ serta berpakaian seragam kader $(67,7 \%)$ dan bidan (100\%). Keadaan tersebut menunjukkan bahwa penampilan kader dan bidan sudah sesuai dengan yang diharapkan oleh masyarakat.

Ketepatan jam buka pelaksanaan posyandu yang sudah sesuai dengan jadwal yang telah ditentukan $(80,2 \%)$, dan kadangkadang berubah $(18,8 \%)$. Jam buka posyandu mulai dari jam 8.00, persiapan penimbangan dan jam 9.00-11.00. Keandalan petugas dalam memberikan pelayanan terhadap anggota posyandu > 90\% sudah terampil, cekatan, memahami tugas dalam memberikan pelayanan, serta memiliki daya tahan fisik yang prima. Kegiatan di posyandu pada umumnya adalah penimbangan, 12 kali/setahun, pengukuran LILA pada ibu hamil rata-rata 5 kali dan pelayanan kesehatan kurang lebih 2 kali/setahun serta penyuluhan gizi dan kesehatan atau pelaksanaan KIE sangat kurang rata-rata $1 \mathrm{kali} / \mathrm{setahun}$. Perhatian petugas pada balita yang mengalami masalah khususnya balita yang hasil timbangannya berada di bawah garis merah kader $(93,8 \%)$ dan perhatian bidan $(91,7 \%)$, perhatian pada ibu hamil baik kader maupun bidan masing-masing (81,3\%) dan (88,5\%), sedangkan perhatian petugas terhadap ibu balita, ibu menyusui dan WUS masih rendah yaitu kurang dari $30 \%$.

\section{Gap Analysis berdasarkan Lima Dimensi Service Quality di Posyandu}

Gap analysis program gizi dan kesehatan di posyandu menunjukkan bahwa bersadarkan dimensi tangibles atau fisik yang dimiliki oleh posyandu adalah sebagai berikut kondisi peralatan yang meliputi jenis dan kemutahiran alat yang dimiliki posyandu ratarata realisasinya 0,66 masih dibawah nilai rata-rata harapan 4,53 serta gap antara realisasi dengan harapan $(\mathrm{R}-\mathrm{H})$ adalah $-0,69$, dengan demikian kondisi alat-alat di posyandu tergolong pada kategori kurang karena realisasinya baru mencapai $31 \%$, sehingga masih jauh dari harapan. Sedangkan kondisi SDM yang meliputi rata-rata realisasi kerapihan penampilan kader adalah $(4,17)$ dan petugas lainnya $(4,41)$ di posyandu termasuk pada kategori sangat baik nilai gap yang diperoleh 0,03, artinya kondisi SDM realisasinya sudah mencapai 97\%, sedangkan rata-rata dimensi tangibles secara keseluruhan nilai gap $-0,35$ artinya bahwa pencapaiannya sebesar $65 \%$, dapat dilihat pada (Tabel 2).

Gap analysis program gizi dan kesehatan di posyandu berdasarkan dimensi reliability. Rata-rata dari realisasi kesesuaian pelaksanaan pelayanan dengan jadwal yang telah ditentukan adalah 4,29 sedangkan ratarata dari harapan adalah 4,20 artinya bahwa antara realisasi dengan harapan termasuk pada kategori sangat baik dengan nilai gap antara realisasi dengan harapan $(\mathrm{R}-\mathrm{H})$ adalah 0,04. Demikian juga ketepatan waktu pelayanan sesuai dengan jadwal yang telah ditentukan rata-rata realisasinya 4,41 dan rata-rata harapan 4,20 dengan nilai gap antara realisasi dengan harapan $(\mathrm{R}-\mathrm{H})$ adalah 0,07, termasuk kategori sangat baik. Rata-rata keseluruhan dimensi reliability nilai gap $-0,10$, artinya pencapaiannya sudah $90 \%$ dengan demikian perlu dipertahankan. 
Tabel 1. Statistik Gap antara Realisasi terhadap Harapan dan Standar Alat-alat yang Dimiliki Posyandu

\begin{tabular}{|c|c|c|c|c|c|c|c|c|c|c|c|c|}
\hline \multirow{2}{*}{ No } & \multirow{2}{*}{ Nama Alat } & \multirow{2}{*}{$\begin{array}{c}\text { Standar } \\
\text { mean }\end{array}$} & \multicolumn{2}{|c|}{ Realisasi } & \multicolumn{2}{|c|}{ Harapan } & \multicolumn{2}{|c|}{ Gap (R-H) } & \multicolumn{2}{|c|}{ Gap (R-S) } & \multicolumn{2}{|c|}{ Gap $(\mathrm{H}-\mathrm{S})$} \\
\hline & & & mean & $\begin{array}{l}\text { Standar } \\
\text { deviasi }\end{array}$ & mean & $\begin{array}{l}\text { Standar } \\
\text { deviasi }\end{array}$ & mean & $\begin{array}{l}\text { Standar } \\
\text { deviasi }\end{array}$ & mean & $\begin{array}{r}\text { Standar } \\
\text { deviasi }\end{array}$ & mean & $\begin{array}{r}\text { Standar } \\
\text { deviasi }\end{array}$ \\
\hline 1 & Timbangan dacin & 2 & 1.04 & 0.20 & 1.59 & 0.53 & -0.27 & 0.26 & -0.48 & 0.10 & -0.20 & 0.27 \\
\hline 2.1 & Meja & 5 & 2.33 & 1.34 & 3.14 & 1.48 & -0.24 & 0.31 & -0.53 & 0.27 & -0.37 & 0.30 \\
\hline 2.2 & Kursi & 10 & 2.74 & 1.62 & 5.64 & 6.38 & -0.37 & 0.33 & -0.73 & 0.16 & -0.44 & 0.64 \\
\hline 3 & Timbangan injak digital & 1 & 0.01 & 0.10 & 1.06 & 0.24 & -0.99 & 0.05 & -0.99 & 0.10 & 0.06 & 0.24 \\
\hline 4 & Timbangan injak jarum & 1 & 1.02 & 0.20 & 1.42 & 0.52 & -0.20 & 0.26 & 0.02 & 0.20 & 0.42 & 0.52 \\
\hline 5 & $\begin{array}{l}\text { Timbangan bayi (babby } \\
\text { scale) }\end{array}$ & 1 & 0.66 & 0.50 & 1.16 & 0.36 & -0.42 & 0.46 & -0.34 & 0.50 & 0.16 & 0.36 \\
\hline 6 & Microtoise & 2 & 0.49 & 0.50 & 1.09 & 0.29 & -0.54 & 0.49 & -0.76 & 0.25 & -0.45 & 0.15 \\
\hline 7 & Alat ukur TB/ PB & 2 & 0.67 & 0.54 & 1.19 & 0.42 & -0.44 & 0.46 & -0.67 & 0.27 & -0.41 & 0.21 \\
\hline 8 & Alat ukur LILA & 2 & 0.31 & 0.51 & 1.25 & 0.60 & -0.76 & 0.40 & -0.84 & 0.25 & -0.38 & 0.30 \\
\hline 9 & Alat ukur tekanan darah & 1 & 0.21 & 0.41 & 1.07 & 0.26 & -0.81 & 0.39 & -0.79 & 0.41 & 0.07 & 0.26 \\
\hline 10 & Kotak P3K & 1 & 0.41 & 0.63 & 1.20 & 0.57 & -0.69 & 0.44 & -0.59 & 0.63 & 0.20 & 0.57 \\
\hline 11 & $\begin{array}{l}\text { Buku-buku Gizi dan } \\
\text { Kesehatan }\end{array}$ & 5 & 0.65 & 1.27 & 8.88 & 6.84 & -0.85 & 0.29 & -0.87 & 0.25 & 0.78 & 1.37 \\
\hline 12 & Buku Pegangan Kader & 5 & 0.69 & 1.15 & 4.46 & 2.46 & -0.79 & 0.34 & -0.86 & 0.23 & -0.11 & 0.49 \\
\hline 13 & Majalah,Tabloid & 5 & 0.17 & 0.79 & 9.63 & 6.44 & -0.96 & 0.16 & -0.97 & 0.16 & 0.93 & 1.29 \\
\hline 14 & Poster & 5 & 1.97 & 1.69 & 4.66 & 2.64 & -0.52 & 0.39 & -0.61 & 0.34 & -0.07 & 0.53 \\
\hline 15 & Leaflet & 5 & 0.16 & 0.69 & 26.33 & 19.76 & -0.96 & 0.16 & -0.97 & 0.14 & 4.27 & 3.95 \\
\hline 16 & Lembar Balik & 5 & 0.08 & 0.31 & 8.54 & 14.51 & -0.94 & 0.23 & -0.98 & 0.06 & 0.71 & 2.90 \\
\hline 17 & Modul & 5 & 0.30 & 1.28 & 8.36 & 6.72 & -0.93 & 0.23 & -0.94 & 0.26 & 0.67 & 1.34 \\
\hline 18 & Tempat Sampah & 2 & 0.68 & 0.67 & 1.70 & 0.62 & -0.60 & 0.39 & -0.66 & 0.34 & -0.15 & 0.31 \\
\hline 19 & Tempat Cuci Tangan & 2 & 0.13 & 0.33 & 1.10 & 0.34 & -0.89 & 0.31 & -0.94 & 0.17 & -0.45 & 0.17 \\
\hline 20 & Lemari/Rak Buku & 3 & 0.34 & 0.63 & 1.19 & 0.44 & -0.75 & 0.42 & -0.89 & 0.21 & -0.60 & 0.15 \\
\hline 21 & Model/contoh makanan & 5 & 0.13 & 0.73 & 8.46 & 4.61 & -0.98 & 0.14 & -0.98 & 0.15 & 0.69 & 0.92 \\
\hline 22 & Dipan/Kasur & 1 & 0.10 & 0.31 & 1.01 & 0.10 & -0.90 & 0.30 & -0.90 & 0.31 & 0.01 & 0.10 \\
\hline \multicolumn{2}{|c|}{ Total } & & 15,27 & 16.40 & 104.11 & 77.16 & -15.81 & 7.19 & -17.26 & 5.75 & 5.33 & 17.34 \\
\hline \multicolumn{2}{|c|}{ Rataan } & & 0,66 & 0.71 & 4.53 & 3.35 & -0.69 & 0.31 & -0.75 & 0.25 & 0.23 & 0.75 \\
\hline
\end{tabular}


Tabel 2. Gap Analysis Program Gizi dan Kesehatan di Posyandu

\begin{tabular}{|c|c|c|c|c|c|c|c|}
\hline \multirow{2}{*}{ Dimensi } & \multirow{2}{*}{ Indikator Kualitas Pelayanan } & \multicolumn{2}{|c|}{ Realisasi } & \multicolumn{2}{|c|}{ Harapan } & \multicolumn{2}{|c|}{ Gap (R-H) } \\
\hline & & mean & std & mean & std & mean & std \\
\hline \multirow{6}{*}{$\begin{array}{l}\text { Tangibles } \\
\text { (fisik) }\end{array}$} & 1. Kondisi peralatan: kemutahiran/kemoderenan peralatan yang dimiliki Posyandu & 0,66 & 0,71 & 4,53 & 3,35 & $-0,69$ & 0,31 \\
\hline & 2. Kenyamanan/ kebersihan tempat penimbangan & 3,03 & 0,83 & 4,61 & 0,60 & $-0,35$ & 0,12 \\
\hline & 3. Kondisi SDM: a. Kerapihan penampilan kader & 4,17 & 0,64 & 4,65 & 0,62 & $-0,10$ & 0,10 \\
\hline & b. Petugas lainnya di Posyandu & 4,41 & 0,53 & 4,59 & 0,61 & $-0,03$ & 0,11 \\
\hline & 4. Kelengkapan: Penampilan fasilitas fisik (sebanding dengan jenis jasa yang diberikan) & 1,98 & 0,75 & 4,70 & 0,51 & $-0,59$ & 0,13 \\
\hline & Rata-rata & & & & & $-0,35$ & 0,16 \\
\hline \multirow{6}{*}{$\begin{array}{l}\text { Reliability } \\
\text { (keandalan) }\end{array}$} & 1. Kesesuaian pelaksanaan pelayanan dengan jadwal yang telah ditentukan & 4.29 & 0.68 & 4.20 & 0.85 & 0.04 & 0.14 \\
\hline & $\begin{array}{l}\text { 2. Perhatian petugas terhadap peserta Posyandu yang mendapatkan masalah } \\
\text { 3. Keandalan petugas Posyandu dalam memberikan pelayanan dari awal hingga akhir pelaksanaan }\end{array}$ & 3.01 & 1.12 & 4.27 & 0.83 & -0.32 & 0.17 \\
\hline & program & 3.58 & 0.79 & 4.23 & 0.81 & -0.15 & 0.14 \\
\hline & 4. Ketepatan waktu pelayanan sesuai dengan jadwal yang telah ditentukan & 4.41 & 0.66 & 4.20 & 0.87 & 0.07 & 0.13 \\
\hline & 5. Keakuratan/ pengadministrasian catatan/ dokumen oleh petugas Posyandu & 3.58 & 0.72 & 4.28 & 0.80 & -0.16 & 0.12 \\
\hline & Rata-rata & & & & & -0.10 & 0.14 \\
\hline \multirow{5}{*}{$\begin{array}{l}\text { Responsive-ness } \\
\text { (ketanggapan) }\end{array}$} & 1. Kejelasan informasi dalam penyampaian jasa & 2.09 & 1.12 & 4.50 & 0.66 & -0.54 & 0.24 \\
\hline & 2. Kesediaan petugas Posyandu memberikan layanan dengan cepat & 3.10 & 0.64 & 4.51 & 0.66 & -0.31 & 0.10 \\
\hline & $\begin{array}{l}\text { 3. Kesediaan petugas Posyandu dalam membantu kesulitan yang dihadapi anggota/ ibu balita/ } \\
\text { bumil/WUS } \\
\text { 4. Keluangan waktu petugas Posvandu untuk menanggapi permintaan anggota/ ibu balita dengan }\end{array}$ & 3.22 & 0.80 & 4.55 & 0.65 & -0.30 & 0.12 \\
\hline & 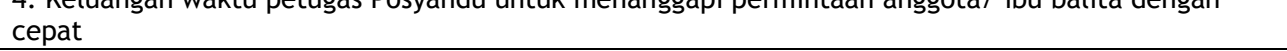 & 3.05 & 1.12 & 4.51 & 0.70 & -0.35 & 0.18 \\
\hline & Rata-rata & & & & & -0.37 & 0.16 \\
\hline \multirow{5}{*}{$\begin{array}{c}\text { Assurance } \\
\text { (keterjami-nan) }\end{array}$} & 1. Kompetensi/ kemampuan petugas posyandu (kader dll) dalam memberikan penyuluhan/ konsultasi & 1.93 & 0.95 & 4.35 & 0.75 & -0.57 & 0.16 \\
\hline & 2. Perasaan aman/ nyaman selama berhubungan dengan petugas Posyandu (kader. dll) & 2.79 & 1.20 & 4.43 & 0.69 & -0.39 & 0.20 \\
\hline & $\begin{array}{l}\text { 3. Kesabaran petugas Posyandu (kader.dll) dalam memberikan layanan } \\
\text { 4. Dukungan Pemerintah kepada petugas Posyandu (kader. dll) untuk melaksanakan tugasnya dengan }\end{array}$ & 3.66 & 0.54 & 4.43 & 0.76 & -0.16 & 0.11 \\
\hline & baik & 1.61 & 0.76 & 4.45 & 0.69 & -0.65 & 0.13 \\
\hline & Rata-rata & & & & & -0.44 & 0.15 \\
\hline \multirow{6}{*}{$\begin{array}{l}\text { Empathy } \\
\text { (empati) }\end{array}$} & 1. Perhatian Pemerintah terhadap petugas Posyandu (kade. $\mathrm{dll}$ ) & 1.52 & 0.60 & 4.57 & 0.64 & -0.67 & 0.10 \\
\hline & 2. Perhatian personal petugas Posyandu (kader. dll) kepada anggota/ ibu balita/ bumil/ WUS & 3.29 & 0.72 & 4.56 & 0.66 & -0.28 & 0.11 \\
\hline & 3. Perhatian personal petugas Posyaandu (Bidan. dll) & 3.31 & 0.64 & 4.55 & 0.66 & -0.27 & 0.11 \\
\hline & 4. Pemahaman petugas Posyandu (kader. $\mathrm{dll}$ ) akan kebutuhan anggota/ ibu balita/ bumil/ WUS & 2.65 & 0.81 & 4.56 & 0.65 & -0.43 & 0.12 \\
\hline & 5. Keluwesan/ fleksibilitas jam buka Posyandu dengan kebutuhan anggota/ ibu balita/ bumil/ WUS & 1.47 & 0.79 & 4.56 & 0.65 & -0.68 & 0.15 \\
\hline & Rata-rata & & & & & -0.47 & 0.12 \\
\hline
\end{tabular}


Gap analysis program gizi dan kesehatan di posyandu bersadarkan dimensi responsiveness nilai rata-rata secara keseluruhan nilai gap adalah -0,37 termasuk pada kategori cukup. Keadaan tersebut menunjukkan bahwa ketanggapan dari petugas posyandu dalam memberikan layanan dengan cepat, membantu kesulitan yang dihadapi ibu balita serta keluangan waktu petugas posyandu untuk menanggapi permintaan ibu balita dengan cepat, perlu ditingkatkan lagi karena pencapaiannya baru mencapai 63\%. Gap analysis rogram gizi dan kesehatan di posyandu bersadarkan dimensi assurance nilai rata-rata keseluruhan nilai gap adalah -0,44, artinya pencapaiannya baru 56\%, tergolong kategori kurang. Gap analysis program gizi dan kesehatan di posyandu bersadarkan dimensi empathy, perhatian pemerintah terhadap kader nilai gap antara realisasi dengan harapan (R-H) adalah $-0,67$, artinya pencapaiannya baru 33\%, termasuk pada kategori kurang. Sedangkan rata-rata keseluruhan nilai gap adalah $-0,47$, artinya pencapaiannya baru $53 \%$, termasuk kategori kurang dan menunjukkan bahwa empati petugas posyandu terhadap ibu balita, ibu hamil dan WUS perlu ditingkatkan karena belum sesuai apa yang diharapkan.

Realisasi alat-alat yang dimiliki posyandu termasuk pada kategori kurang, dengan demikian agar kegiatan di posyandu berjalan lancar, sebaiknya alat-alat yang diperlukan untuk melakukan kegiatan penimbangan, atau kegiatan lainnya seperti penyuluhan gizi dan kesehatan sebaiknya ada di posyandu sesuai dengan standar alat ideal untuk melayani 50 anggota posyandu.

\section{KESIMPULAN}

Gap analysis berdasarkan lima dimensi yaitu tangibles, reliability, responsivenes, assurance, dan empathy secara keseluruhan menunjukkan nilai negatif sehingga perlu ditingkatkan karena masih kurang dari yang diharapkan.

Pelaksanaan program gizi dan kesehatan di posyandu, pelaksanaan KIE, pelayanan kesehatan belum berjalan dengan baik karena terkendala tempat, SDM, media dan alat-alat yang masih belum memadai.

\section{DAFTAR PUSTAKA}

Berita Resmi Statistik. 2009. Berita Resmi Statistik No 43/07/Th. XII, 1 Juli 2009, Jakarta.

2004. Profil Kesehatan Indonesia, Menuju Indonesia Sehat 2010, Jakarta.

2008. Riset Kesehatan Dasar (Riskesdas 2007). Badan Penelitian dan Pengembangan Kesehatan. Depkes, Jakarta.

Jazid J. 1991. Hubungan Peran Kader dalam Pengelolaan dengan Penampilan Posyandu di Kodya Pangkal Pinang. Tesis Program Pascasarjana. Fakultas Kesehatan Masyarakat Universitas Indonesia, Jakarta.

Lupiyoadi R. 2001. Manajemen Pemasaran Jasa (Teori dan Praktek). Salemba Empat. LSOM Laboratorium Studi Manajemen. Jurusan Manajemen FE UI, Jakarta.

Muslimatun S. 2001. Nutrition of Indonesia Women During Pregnancy and Lactation : A focus on Vitamin A and Iron. Thesis Wageningen University, The Netherlandswith summary in Ducth and Indonesian.

NugrohoW S. 2004. Analisis Kepuasan Pelanggan Orlen Automatic car Wash and Saloon Jakarta. Tesis Program Pascasarjana. Manajemen Agribisnis. IPB, Bogor.

Parasuraman A, Zeithalm V, Berry L. 1988. SERVQUAL: A Multiple Item Scale for Measuring Consumer Perceptions of Service Quality. Journal of Retaliling.

Puspasari A. 2002. Faktor-faktor yang Mempengaruhi Kinerja Kader Posyandu di Kota Sabang Propinsi Nangroe Aceh Darussalam. Skripsi Sarjana Gizi Masyarakat dan Sumberdaya Keluarga. Fakultas Pertanian, IPB, Bogor. 